\title{
Improved Retention and Other Impacts Benefiting Engineering Technology Undergraduates Involved in High School Outreach
}

\section{Dr. Christina R Scherrer, Southern Polytechnic State University}

Christina Scherrer is an Associate Professor of industrial engineering technology at Southern Polytechnic State University. Her research interests are in the application of operations research and economic decision analysis to the public sector and in assessing education innovation. She teaches primarily statistics and logistics courses, at both the undergraduate and graduate level. She received her Ph.D. in industrial engineering from the Georgia Institute of Technology. 


\title{
Improved Retention and Other Impacts Benefiting Engineering Technology Undergraduates Involved in High School Outreach
}

\begin{abstract}
:
Retention of engineering technology undergraduates remains a problem, especially for students from underrepresented groups in the field. In this paper we report on the impact that performing outreach has had on engineering technology students involved in an outreach program focused on educating high school students on the ways engineers help the world. To do this, we interviewed all of the past and current undergraduate outreach participants and performed qualitative analysis. Specifically, we studied how they believe their participation has affected their interest in remaining in an engineering technology major, their likelihood of going to graduate school, and their interest in future involvement in K-12 STEM education programs.
\end{abstract}

\section{Introduction and Literature Review}

Retention of engineering technology undergraduates remains a problem, especially for students from underrepresented groups in our field. Various studies show that in the vicinity of $40 \%$ of students who enroll in engineering-type majors do not graduate with an engineering degree ${ }^{1-4}$. At Southern Polytechnic State University, only 30.9\% of first-time freshman entering the school of Engineering Technology and Management (ETM) in Fall 2006 had graduated with an ETM degree by Spring 2012. These graduation rates tend to be even lower for females and for black or Hispanic students ${ }^{3}$ - demographics already underrepresented in the majors. Improving these statistics is important to meet the need for engineers in the years ahead. In addition, motivating promising undergraduate students to pursue graduate study in science, technology, engineering and mathematics (STEM) fields is a desirable outcome. Therefore, in this research we study the positive impact that involvement in a high school outreach effort has had on the undergraduates performing that outreach.

There is a large body of literature on the impact of undergraduate research experiences on their participants. There is strong evidence for improvements in retention as well as in the percentage of students who pursue graduate degrees. For example, a large study of nearly 15,000 undergraduates funded by the National Science Foundation ${ }^{5}$ found that undergraduate students who participate in hands-on research are more likely to pursue advanced degrees in STEM fields. In a study of factors that promote student retention and success, Nagda et al. ${ }^{6}$ have shown that undergraduate research increases retention rates in science and engineering programs, particularly for African-Americans and sophomores. Lopatto ${ }^{7}$ surveyed more than 1,100 science undergraduate students who had participated in undergraduate research and found that $83 \%$ intended to continue in science-related graduate education, and that the percentage was the same for underrepresented groups in STEM fields. In another study of 36 undergraduate minorities who had participated in a summer research program, Morley et al. ${ }^{8}$ found $92 \%$ of the students either were enrolled in a graduate program or had plans to enroll within two years. Zydney et al.

9 studied a group of their university's alumni, matching a set of undergraduate research program participants to a set of individuals who resembled the participants except for the fact that they did 
not participate in undergraduate research. They also found that alumni with research experience were more likely to pursue graduate degrees.

There is also a significant literature on the varied successes of outreach programs at recruiting undergraduates. However, little research has been published on the impact that performing the outreach has had on the undergraduate students that are performing the outreach. In an exception, Karp et al. ${ }^{10}$ implemented an elementary outreach program using Lego NXT and tracked the retention of undergraduates involved as mentors/engineering instructors to the elementary students. While the study did not collect quantitative data, the authors believed that the engineering students gained self-esteem and improved their problem-solving and communications skills and that their participation also positively influenced their perception of their choice of major. Switzer and Benson ${ }^{11}$ also studied the impact of outreach activities on undergraduate students performing them, specifically as it pertained to their motivation. One hundred sixty students were involved in creating physical models and activities to demonstrate math, physics or chemistry concepts to high school students. In this case, a survey instrument was used to assess the students' attitude toward their engineering program both before and after a three-week design project. No statistically significant change in motivation over time was found, though the authors believe the short time horizon was a factor. In this study, we attempt to address this research gap and gather further information about the impact that performing outreach has on undergraduate students.

\section{Methods}

For the past three years, the author, an associate professor at a polytechnic university, has directed a high school outreach program in which undergraduate students from our university visit local schools in teams to teach the middle and high school students how engineers can "do good" in the world. The outreach was motivated by evidence that emphasizing the social good of engineering at the K-12 level could increase participation in engineering, especially among some traditionally underrepresented groups in the engineering field. The outreach was funded by a National Science Foundation BRIGE grant. Details about the outreach program, as well as quantitative assessment of the impact on the high school students' perceptions of engineering, can be found in Scherrer (2012) ${ }^{12}$. In this paper we report on the impact performing the outreach has had on the engineering technology students performing the outreach. Specifically, we study how their participation has affected their interest in remaining in an engineering technology major and career, their likelihood of going to graduate school, and their interest in K-12 STEM education.

Ten of the eleven undergraduate students performing the outreach were engineering technology majors (the eleventh is an engineering major) and all but one were from underrepresented groups in engineering. The outreach project has been primarily undergraduate student led, and students were paid by the hour for their involvement. In the first year of the grant, students designed the 'first generation' of hands-on projects that were used in the presentations. The author worked together with the students to design the Powerpoint presentation, brochures, and survey instruments. Later students updated the projects and presentation based on feedback from the middle and high schools. Each semester one undergraduate student was in charge of making the 
contacts with the schools, scheduling visits, and coordinating the rest of the team. This involved finding team members to prepare and purchase supplies as well as determine who would be performing each visit. Thus far, a total of 42 presentations have been given to 18 schools reaching more than 1,200 students.

With a goal of determining the impact of the outreach on undergraduate participants, the author surveyed the students who have been involved in the outreach as undergraduates (referred to as 'students' in the remainder of the paper). The survey questions are included in the appendix. With the small group of students involved and the author's personal relationship with all of the students, anonymity wasn't possible for the survey. However, we believe that a level of trust has been built that allowed them to be candid in their responses. The survey had $100 \%$ participation from the students.

\section{Results}

Responses to the survey questions are combined into three basic categories below: perceived benefits and drawbacks, impact on the students' future, and their impression of K-12 STEM education.

\section{Perceived benefits and drawbacks}

Students were asked about the most meaningful part of the program for them. All highlighted some aspect of the opportunity to shape another person's future for the better. A quote from one student was, "The most meaningful part of the program is getting pre-college students thinking about their own future. It is hard to aim for a goal that you do not know exists. This was an opportunity to show kids potential future direction which would help them learn about a career that performs well from a monetary earning standpoint as well as contributes greatly to society's development." Several mentioned that they wished they had been exposed to a similar program as high school students themselves and one mentioned that a different outreach program (FIRST Robotics) had influenced their decision to pursue an engineering technology degree.

When asked about the biggest personal benefit to them, most students (eight) focused on the improvements in their communication skills. Several noted that these skills have helped them in other classes as well as at their internship or full-time job. Many also mentioned giving them confidence in and additional excitement about their major and career choice (five). Other benefits mentioned were the personal satisfaction that comes from helping others, the opportunity to work in a team, and the financial benefit.

Most students said that there were no drawbacks to participation in the program. Two students mentioned the difficulties of working with a team, and sometimes being let down by team members. Two students mentioned the difficulty of balancing this activity with the other activities in which they were involved. One student who had served as a coordinator mentioned frustration that schools she knew could benefit from the outreach did not want to put forth the effort to reply to our inquiries and let the team come. 
All of the students said that they would recommend participation in an outreach program to other undergraduates, and agreed that it had been very beneficial for them. One quote was, "Having people closer to their age come and talk about engineering and how exciting it CAN be (if you're passionate about it) is a breath of fresh air," while another student said, "I think that anyone with a passion for what they are doing would benefit from an experience like this because passion is contagious. They'd be able to help students see that college isn't all homework and papers. You get to start working on what you love!" And a third student said, "It is not only a fulfilling experience, but it is extremely fun and you can learn a lot from it at the same time".

\section{Impact on students' future}

Students were questioned on the impact their participation had on their major choice, their likelihood to graduate with an engineering technology degree, and their likelihood of attending graduate school. At the time of this writing, five of the eleven students have completed their engineering technology degree. Three have petitioned to graduate next semester, two are on track to graduate within the year (one of these is the lone engineering major), and one (who already had a bachelors' degree in a non-STEM major) has chosen to pursue a masters degree in science/engineering education at another university. Of the alumni, one is in graduate school full-time and the other four are working full-time as engineers.

None of the students felt that their participation affected their completion of their current degree. Most noted that they were upperclassmen at the time they began and were committed to the degree they had chosen at that point. Along those lines, several mentioned that it solidified their interest in their major, but that they would still have completed their degree. Similarly, most of the students said that it did not impact their decision to pursue a graduate degree. However, two students said that they are now considering getting PhDs, when they had previously been planning on getting an MBA. In addition, the student mentioned above chose to pursue a masters of education degree rather than continue the second undergraduate degree. The graduate degree plans of the eleven students are summarized in Table 1.

\begin{tabular}{|l|c|}
\hline Graduate degree plans & Number of students \\
\hline Accepted or enrolled in MS STEM program & 1 \\
\hline Plan on MS in a STEM field in the future & 3 \\
\hline Accepted or enrolled in MBA program & 2 \\
\hline Plan on MBA in the future & 2 \\
\hline Plan on either a masters or PhD in the future & 2 \\
\hline No current plans for a graduate degree & 1 \\
\hline
\end{tabular}

Table 1: Graduate study plans of program participants

Perceptions of the K-12 STEM system

We were also interested in whether the students' participation made them more likely to be involved in the K-12 STEM education system in the future. When questioned about their 
attitudes toward K-12 STEM education, the students had mixed feelings. Most mentioned that they wished there were more opportunities for middle and high school students to be exposed to engineering. Several mentioned a significant difference between students at the various schools, in terms of their backgrounds and their understanding of engineering.

About half of the students said that they would not rule out teaching high school in the future if there were an easy pathway to that career option. Several others said they would like to be involved in a mentoring program of some sort for the age group. Another student said participation in the program made her realize she would like to teach engineering, but at the college level.

\section{Conclusions}

In general, students found their participation in the outreach project to be very beneficial, both from an altruistic standpoint and in improving their communication skills. The participants perceived little impact on their education and career plans based on their participation. However, all of the students have graduated or are on a successful trajectory toward graduating soon, and most of the students are planning to pursue graduate degrees. Due to the effort required to apply and the interview process for selection, the program was able to recruit top students that were likely to succeed without involvement in such a program. However, the students appear to have learned skills that will help them to be more successful in those future endeavors.

There are some shortcomings of this work. The sample size is small, as there were only eleven students involved in our outreach project. Thus far, we have only been able to follow those students over a short time horizon. It would be interesting to see how many actually complete graduate degrees. Perhaps the biggest weakness is that the students involved in the project, and in most any undergraduate outreach project, have a self-selection bias in that they are students motivated to apply for such positions and to share engineering with others. It is likely that participation in the outreach by less motivated students, including those more likely to drop out of engineering technology undergraduate programs, would have yielded significantly different results. In addition, all results are self-reported by the students. It is likely easy for a student to assess their excitement level about sharing their passion for engineering, but may be difficult to accurately evaluate the effects of their participation on degree completion and future plans.

Despite these shortcomings, we believe this research still makes a contribution to an important area of study. While the benefits of undergraduate research toward retention are welldocumented, performing undergraduate research isn't realistic for all students, and may not be as helpful for students who aren't headed to graduate school. However, outreach is something a wider range and larger number of students can do, and it would be ideal if it had the same positive effects on retention as performing research. Students who perform the outreach would be more likely to complete their degree and enter STEM fields, and the students would develop essential communication and team skills to benefit them in those fields. 
We believe that the results from this work may support the inclusion of similar outreach opportunities in the engineering technology curriculum, and starting the outreach opportunities at an earlier point in the students' degree program to have a more significant effect. As many of the students felt that sharing their experiences validated their desire to complete a degree in engineering technology, a similar opportunity may help students who are wavering more in their desire to complete their degree.

\section{Acknowledgements}

The outreach studied in this paper was funded by the National Science Foundation Broadening Participation Research Initiation Grants in Engineering (BRIGE) Award \#0927095. Any opinions, findings, and conclusions or recommendations expressed in this material are those of the authors and do not necessarily reflect the views of the National Science Foundation.

Many thanks to the undergraduate students and alumni who have worked so hard on this outreach project and who were willing to share their insights: Juan Fleming, Jennifer Henry, Yassaman (Yasmine) Jonaidi, Corey Lewis, Chantelle Minarcine, Tiffany Murrell, Thuy (Cindy) Nguyen, Alyssa Perry, Pranita Saraswatula, David Sluder, and Shane Turner.

\section{Bibliography}

1. Flynn, A.M.H. and H. Richard (2003), "A Longitudinal Retention Study in an Urban Engineering School," Proceedings, American Society for Engineering Education Annual Conference, 2003, Nashville, TN.

2. Huang, G.; Taddese, N, and E. Walter (Eds) (2000), Entry and Persistence of Women and Minorities in College Science and Engineering Education. Washington, DC: U.S. Department of Education. National Center for Education Statistis.,NCES 2000-601.

3. Knight, D.; L. Carlson, and J. Sullivan (2007). Improving Engineering Student Retention through HandsOn, Team Based, First-Year Design Projects, Proceedings of the Conference on Research in Engineering Education, June 2007 pp.1-13.

4. National Science Board (2012). Science and Engineering Indicators 2012. Arlington VA: National Science Foundation (NSB 12-01). Chapter 2. Higher Education in Science and Engineering. Available at http://www.nsf.gov/statistics/seind12/c2/c2s2.htm\#s3 Accessed December 18, 2012.

5. Russell, S.H.; M. P. Hancock, and J. McCullough(2007). Benefits of Undergraduate Research Experiences. Science Vol. 316 no. 5824 pp. 548-549

6. Nagda, B.; S. Gregerman, J. Jonides, W. von Hippel, and Jennifer S. Lerner (1998). Undergraduate studentfaculty research partnerships affect student retention. The Review of Higher Education. 22: 55-72.

7. Lopatto, D. (2004). 'Survey of Undergraduate Research Experiences (SURE): First Findings'. Cell Biology Education. Vol. 3, 270-277, Winter 2004.

8. Morley, R.; J. Havick, and G. May (2002). 'An Evaluation of the Georgia Tech Summer undergraduate program of research in electrical engineering for minorities'. Journal of Engineering Education, 87(3): $321-325$.

9. Zydney, A.; J. Bennett, A. Shahid, and K. Bauer (2002). 'Impact of Undergraduate Research Experience in Engineering', Journal of Engineering Education, April 2002.

10. Karp, T.; R. Gale, L. A. Lowe, V. Medina, and E. Beutlich (2010). 'Generation NXT: Building Young Engineers With LEGOs'. IEEE Transactions on Education, Vol. 53, No. 1.

11. Switzer, D. and L. Benson. (2007) 'Assessing Impact of Outreach Activity on Motivation of Undergraduate Engineering Students'. American Society for Engineering Education, AC 2007-2269. 
12. Scherrer, C. (2012). 'Emphasis on the Human Impact Potential of Engineering as Outreach to Underrepresented Groups'. Submitted to Journal of Women and Minorities in Science and Engineering, July 2012.

\section{Appendix}

\section{Survey questions:}

1) What was the most meaningful part of the outreach program for you? Why?

2) In what ways did you most benefit from participation in the outreach?

3) Did your participation in the program have any drawbacks? If so, what?

4) Do you think working on the outreach program impacted whether you completed (or will complete) your undergraduate degree program? Why or why not? Did it impact any changes of major?

5) Are you planning to go to graduate school? If yes, for what degree and when do you plan to go?

6) Did your participation in the outreach project impact your decision to pursue a graduate degree or not? If so, how?

7) How did your participation in the outreach impact your feelings about the K-12 STEM education system?

8) Do you have any interest in in teaching K-12 at some point in the future? Why or why not?

9) Would you recommend participating in an outreach program like this to other undergraduates? Why or why not?

10) If you are currently a student, how many more semesters do you have until you graduate? If you are an alumnus, what are you doing now? 